\title{
One-Pot Synthesis of Cyanuric Acid-Bridged Porphyrin-Porphyrin Dyads
}

Tommaso Carofiglio, * Alessandro Varotto, Umberto Tonellato

Department of Chemical Sciences, University of Padua, Via Marzolo 1, 35131 Padua (Italy) tommaso.carofiglio@unipd.it

Additional Supporting Information

Figures:

S1) ${ }^{1} \mathrm{H}-\mathrm{NMR}$ of compound 5 in $\mathrm{CDCl}_{3}$

S2) ${ }^{1} \mathrm{H}-\mathrm{NMR}$ of compound 6 in $\mathrm{CDCl}_{3}$

S3) ${ }^{1} \mathrm{H}$-NMR of compound $\mathbf{8}$ in $\mathrm{CDCl}_{3}$

S4) ${ }^{1} \mathrm{H}-\mathrm{NMR}$ of compound 9 in $\mathrm{CD}_{2} \mathrm{Cl}_{2}$

S5) ${ }^{1} \mathrm{H}$-NMR of compound $\mathbf{1 1}$ in $\mathrm{CD}_{2} \mathrm{Cl}_{2}$

S6) HPLC traces for compounds $\mathbf{8 , 9 , 1 1}$ 


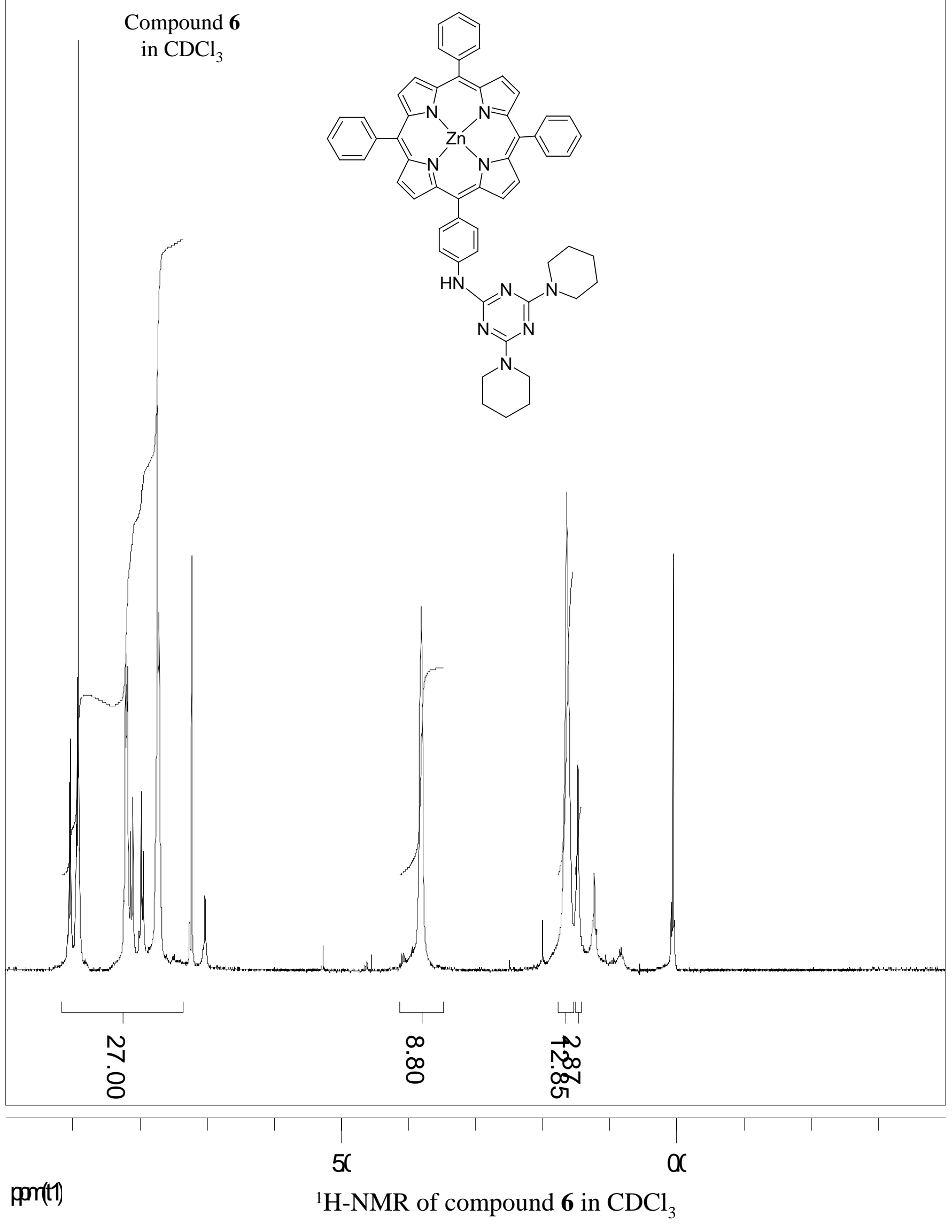


Compound 8

in $\mathrm{CDCl}_{3}$
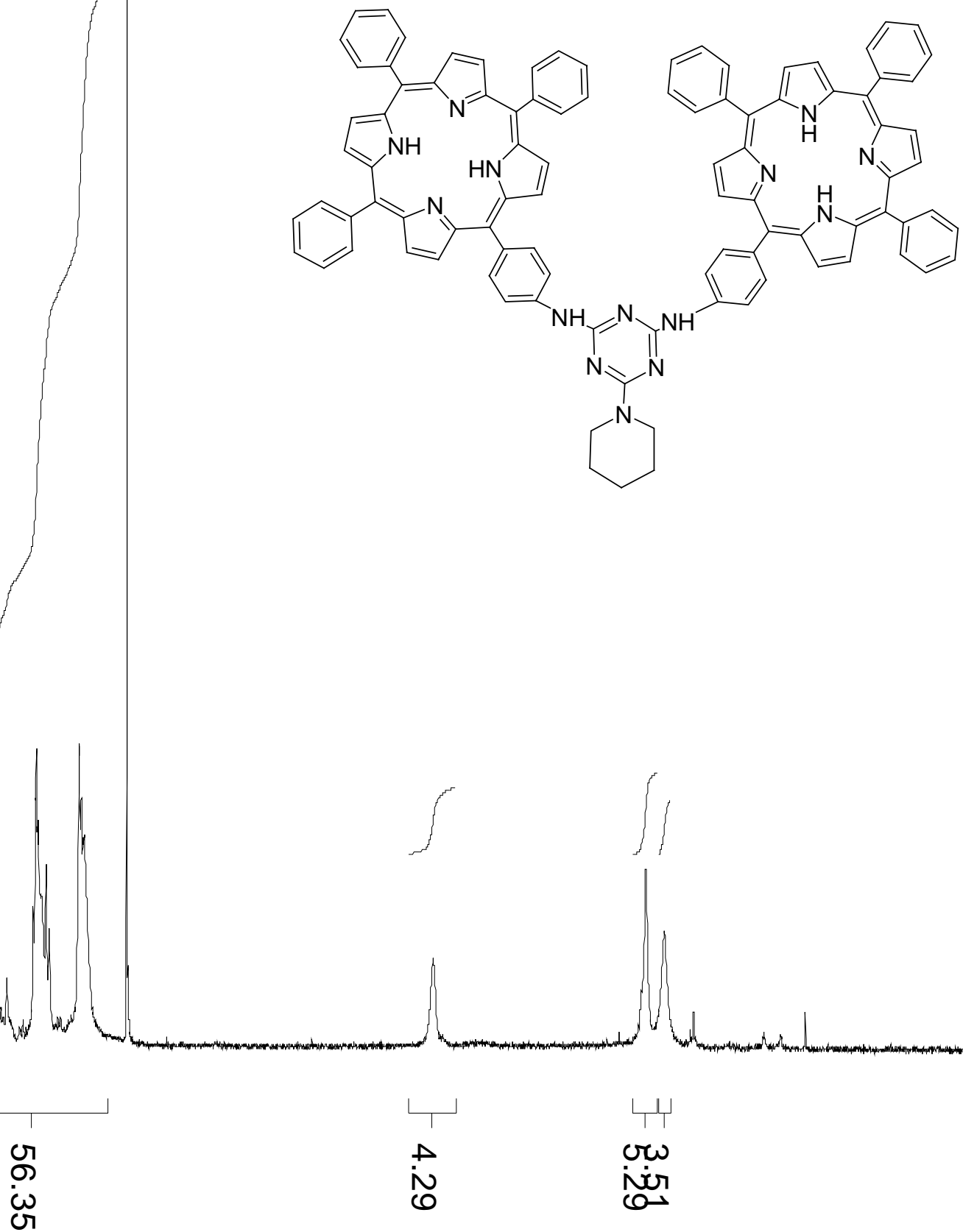

8

port(1)

$5 C$

ac

S3) ${ }^{1} \mathrm{H}-\mathrm{NMR}$ of compound $\mathbf{8}$ in $\mathrm{CDCl}_{3}$ 


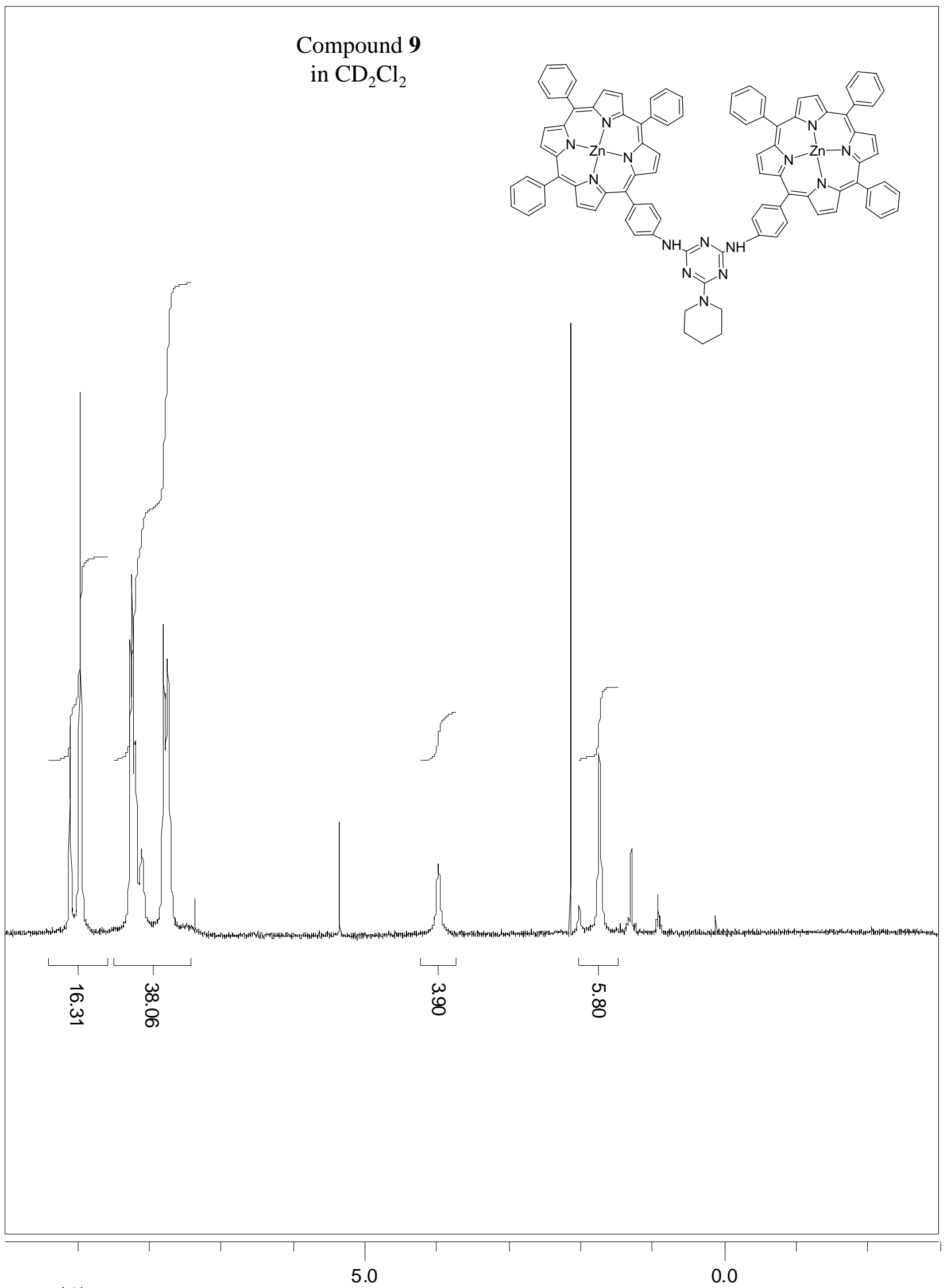

ppm (t1)

S4) ${ }^{1} \mathrm{H}$-NMR of compound 9 in $\mathrm{CD}_{2} \mathrm{Cl}_{2}$ 
Compound 11

in $\mathrm{CD}_{2} \mathrm{Cl}_{2}$

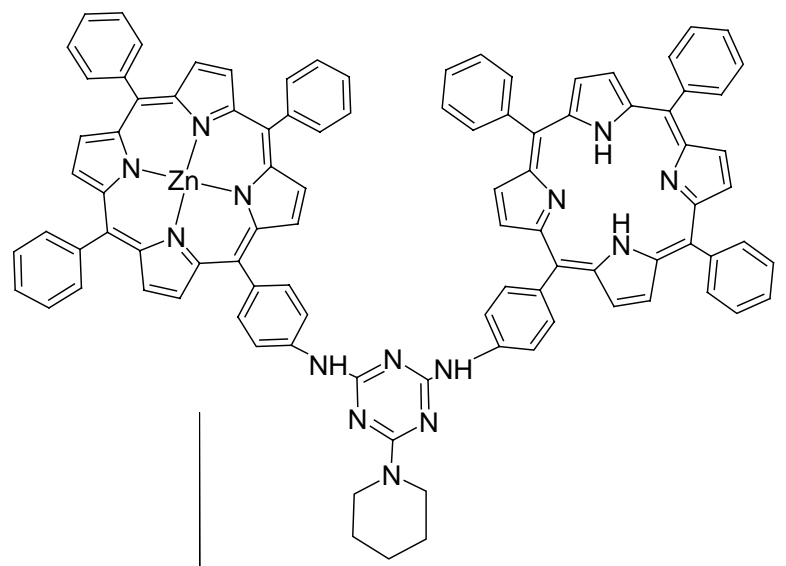

$\begin{array}{ll}\omega & \omega \\ \circ & \infty \\ \dot{8} & \stackrel{\circ}{\ominus}\end{array}$

$\begin{array}{ll}\omega & \stackrel{\sigma}{0} \\ \dot{0} & \text { ज़ }\end{array}$

$\stackrel{\leftrightarrow}{\circ}$ 

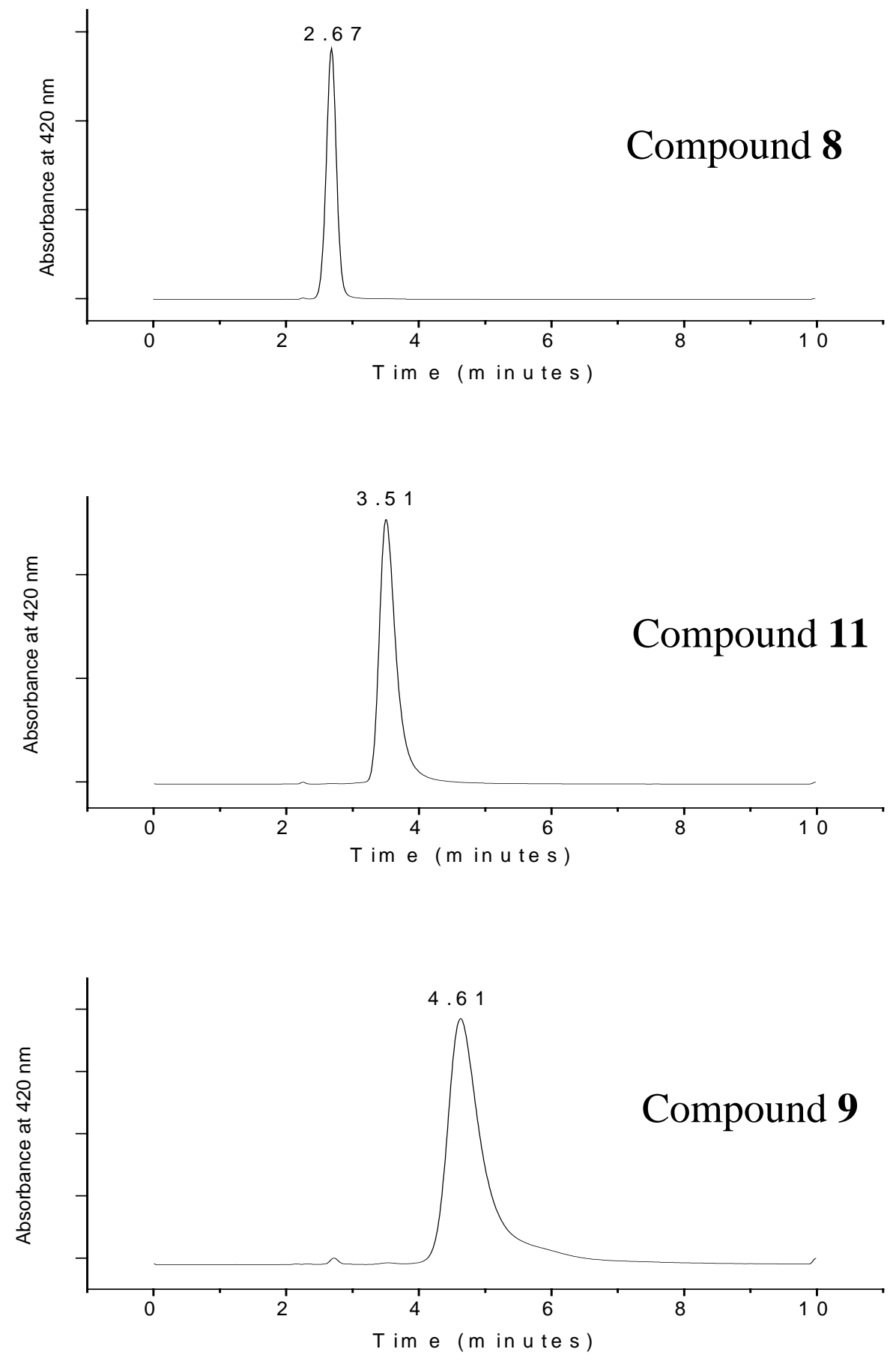

S6) HPLC traces for compounds 8, 9, 11

Column: Econosil Silica 5U, $250 \mathrm{~mm}$ x $4.6 \mathrm{~mm}$

Eluent: $\mathrm{CHCl}_{3}$ :Ethyl Acetate:Triethylamine 96:3.5:0.5 \% in volume Flow: $1.5 \mathrm{ml} / \mathrm{min}$

Detection: UV-Vis at $420 \mathrm{~nm}$ 